\title{
Correction to: The uncertainties and causes of the recent changes in global evapotranspiration from 1982 to 2010
}

\author{
Bo Dong ${ }^{1} \cdot$ Aiguo Dai ${ }^{1,2}$
}

Published online: 17 October 2018

c) Springer-Verlag GmbH Germany, part of Springer Nature 2018

\section{Correction to: Clim Dyn (2017) 49:279-296 \\ https://doi.org/10.1007/s00382-016-3342-x}

In the original publication of the article Fig. 7 was incorrect.

The correct Fig. 7 is given below:

The original article can be found online at https://doi.org/10.1007/ s00382-016-3342-x.

Aiguo Dai

adai@albany.edu

1 Department of Atmospheric and Environmental Sciences, University at Albany, State University of New York, Albany, NY 12222, USA

2 National Center for Atmospheric Research (NCAR), Boulder, CO, USA 

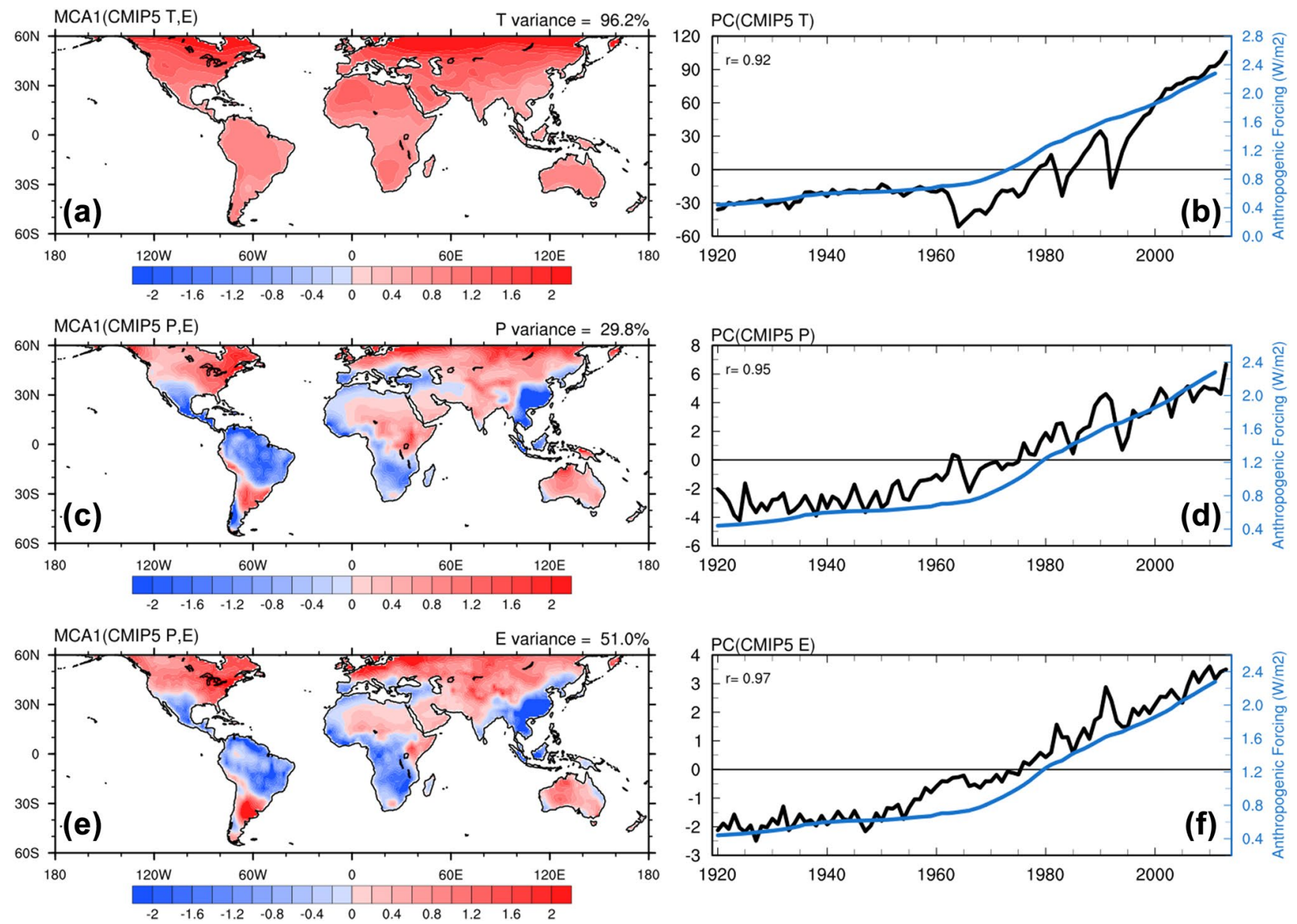

Fig. 7 Spatial patterns (left) and the associated PCs (right, black line) of the 1st MCA mode for CMIP5 multi-model ensemble mean surface air temperature $\mathrm{T}$ (top row), precipitation $\mathrm{P}$ (middle row) and evaporation $\mathrm{E}$ (bottom row) derived from an MCA analysis of, respectively, the CMIP5 model $\mathrm{T}$ and $\mathrm{ET}, \mathrm{P}$ and $\mathrm{ET}$, and $\mathrm{P}$ and $\mathrm{ET}$ from the all-forcing simulations (Taylor et al. 2012). The blue curve in the right panels is the anthropogenic radiative forcing from Figure 8.18 of Myhre et al. (2013). The correlation between the PC and the forcing series is shown inside (b), (d), and (f). The explained percentage variance is shown on top of the $\mathbf{a}, \mathbf{c}$, and $\mathbf{e}$ 